\title{
1 Community Peer Review: A method to 2 bring consent and self-determination 3 into the sciences
}

4 5

${ }^{1}$ Department of Geography, Memorial University of Newfoundland, St. John's, Newfoundland, Canada

${ }^{2}$ Civic Laboratory for Environmental Action Research, St. John's, Newfoundland, Canada

* Corresponding author

Email: mliboiron@mun.ca 


\section{Abstract}

2 Community peer review is a method that extends the ethics of consent into scientific practices. It

3 gives communities affected by scientific research the ability to determine whether research may

4 cause them harm and be part of determining how knowledge should best circulate to reduce or

5 eliminate that harm. This paper introduces the method of community peer review by first looking

6 at the concepts of consent and refusal, then outlining the steps to community peer review, using

7 a case study of community meetings on a study of plastic ingestion by fish to elucidate the

8 details of each step. Steps include: hiring a community member to the team; researching the

9 social, cultural, and economic contexts of the community; identify the community; ensure skills

10 for community conversation are in place; call the community meeting; conduct the community

11 meeting; and analyze feedback for consent and refusal. Community peer review is premised on

12 the idea that research is not inherently good and can cause harm, and that the best people to

13 know whether and what kinds of harms are likely to occur are community members rather than

14 researchers. The second premise is that the researcher's "right" to research never supersedes a

15 community's right to not be harmed.

16

\section{Keywords}

18 Ethics, community, refusal, consent, peer review, community peer review

\section{Introduction}

20 Community peer review is a methodological tool to extend the ethics of consent into scientific

21 practices so communities affected by scientific research are able to determine, with 
1 researchers, how knowledge should circulate so as to reduce harm and increase benefit. This

2 method is based on two premises. First, research is not inherently good and can cause harm to

3 communities, and that the best people to know whether and what kinds of harms are likely to occur are community members rather than researchers $[1,2]$. The second premise is that a researcher's "right" to research or data never supersedes a community's right to not be harmed and to benefit from research. If "[s]cience's peer review depends on openness [and] openness prevents science from becoming dogmatic, uncritical and biased" [3: p.58], then community peer review extends this ethos to a broader form of openness.

At Civic Laboratory for Environmental Action Research (CLEAR), an environmental science and justice laboratory that specializes in marine plastic pollution research, we have designed and tested a method that combines consent, community self-determination, and peer review that we call community peer review. Adapted from methods in the social sciences, community peer review is specifically designed for environmental science that does not have human subjects as part of the original research design. We feel that this method can be adapted and used by a variety of researchers in the natural and physical sciences to extend ethics to areas not usually considered in scientific research and thus mitigate unexpected and unintended harms as well as increase benefit to communities. Indeed, the best place for community review is at the beginning of research rather than at the end, and while community peer review is a method specifically for the end of research and dissemination pathways, much if it can be adapted for gaining consent to conduct research in the first place. This paper first outlines concepts of consent and refusal, the two main terms mobilized by the method, to ground the step-by-step protocol for conducting community peer review. We use a case study to show the nuances of the process and how to analyze results of review. 
1 The aim of this paper is to introduce the concept of community peer review to researchers and

2 outline a method for its use, based on a successful case study.

\section{Research can cause harm}

4 Science is often done to benefit society, but scientific findings can also have negative social,

5 cultural, political, and economic effects. Indeed, institutional ethical guidelines in biomedical,

6 animal, and human research have often been created or adapted when such harms occur, such

7 as the famous Tuskegee syphilis experiments where medical intervention was withheld from

8 Black residents who were used as controls in syphilis treatments [4] and the Stanford prison

9 experiment where students were treated with cruelty to simulate prison conditions [5]. Even

10 when scientists are not intending harm, and are even asking research questions designed to

11 benefit communities, harm has still occurred [6-11]. Researchers cannot always know or

12 anticipate how a community may be affected by their results-communities are in the best

13 position to know [1,2].

\section{Consent}

Consent means that a person or group voluntarily agrees to the proposal or desires of another. Like existing forms of academic peer review, the proposal under consideration in community peer review is the dissemination of the research along certain pathways, usually via academic publishing. Yet unlike academic peer review, community consent or refusal will rarely be so clear as a statement such as, "we reject your submission" or "these are the terms for circulation of this data". Community consent to disseminate knowledge and/or to decrease harm and increase benefit is more nuanced and subtle than academic publishing consent. 
1 Consent in community peer review can be understood through five defining characteristics. The

2 first three reflect the Canada's Tri-Policy Statement for Ethical Conduct on Research Involving

3 Humans, which requires consent be "free, informed and ongoing" [12]. "Free" means that consent must be voluntary, without coercion (such as threats of harm or withholding benefit) or undue influences, such as when a researcher is in a direct power relationship over a research participant. For example, if a research scientist were on the board responsible for distributing fishing licenses to communities, the ability to freely provide a "negative" peer review within that community is compromised. "Informed" consent means people have enough information to fully understand the risks or benefits associated with a research project, including "adequate time and opportunity to assimilate the information provided, [and] pose any questions they may have" [12: p3.2]. The "ongoingness" of consent means that whether and how people consent can change over time and continuous checking in is required. This may include instances where new information about plastic harm becomes available or if a community's political or economic situation were to change.

Community peer review goes beyond individual consent. In a community setting, it is imperative not to conflate individuals' acceptance or rejection of research with that of a community's. Ensuring community-scale consent has challenges, most of which pivot on representational issues such as who is part of the group, how to handle geographically dispersed communities, and problems of agreement and power within communities [13-15]. Our method of community peer review gathers input from individuals in group settings and analyzes input at both the individual and aggregate scales, as we outline in sections below.

Finally, consent is more complex than a simple yes/no framework [16,17]. Obtaining communitylevel consent requires paying attention to the subtle ways in which research practices are consented to or refused simultaneously and unevenly. For example, we have colleagues who 
1 do community-based research and community members routinely welcome them, host them,

2 feed them, and even sign consent forms mandated by human subject ethics, but practice refusal

3 at every other stage of the research: they consistently show up late, don't speak much at

4 meetings unless things are "teased out" of them, they deflect questions, and indicate that some

5 requests are difficult or too confusing to respond to. Even in instances when written consent has

6 been given, these subtle objections to research should be understood as refusal through an

7 absence of other forms of consent $[2,18]$. This is not to say that consent is synonymous with

8 harmony, but that subtle forms of refusal are easy to overlook in the face of confirmation bias. At

9 the same time, refusal or consent of aspects of a research project are not necessarily

10 synonymous with refusal or consent of the entire project. The method of community peer review

11 is designed to allow communities and researchers to work together to ensure a dissemination

12 proposal that reduces harm and increases benefit for communities (see step 4 below in

13 particular).

\section{Refusal}

It is already common in research ethics in the social sciences to disseminate some aspects of research differently than others, or not at all. For example, confidentiality and anonymity of research subjects achieved by withholding or removing certain information, such as people's real names and other identifying features, is a key strategy in research ethics in research involving human subjects. In anthropology, the term "refusal" refers to ethical and methodological considerations about how and whether data should be shared within academia at all, as researchers often encounter information that may be intensely personal, fundamentally contextual, sacred, should only be held by certain people, or needs to be earned. While community members may choose to participate in research projects, they may "refuse" to 
1 engage in particular topics that they do not want known or misrepresented by outsiders. This is

2 their right, as they are refusing to consent to an outside research process $[19,20]$.

3

In refusal, rather than "the terms of accommodation [...] being determined by and in the interests of the hegemonic [more powerful] partner in the relationship" [21: p.17], communities set the terms of how and whether research that impacts their communities should occur, be conducted, and circulate. Practicing refusal emphasizes that gaining knowledge from community participants is not an inherent good. It allows researchers to work together with community members to ensure academic interests are in line with community concerns. Refusal is a way to support the self-determination of communities who are not usually able to govern how they are represented in research and academia. As such, rather than understanding refusals strictly as a form of saying "no", we can also understand it as a way of affirming and strengthening community values and knowledge, and of repairing the often-strained historical relationships between communities and research institutions [2,22].

In community peer review, refusal and consent can occur at two levels. First, there is consent or refusal for publication; whether data and findings should enter the academy rather than say with the community or circulate in ways that exclude the academy. For example, in our case of a study of wild food contamination, community members might not consent to having our study published, but would potentially want it to go to the Fisherman's Union, hospitals, and community members. Second, communities are invited to refuse or consent to specific aspects of the research and have a hand in how or which data is analyzed or how and where future studies might occur, increasing the potential benefit of research to communities. For example, in our case, community members consistently prioritized some species of fish over others, and our lab now focuses on biomonitoring those species for contamination. 


\section{Methods}

2 This section starts with a brief overview of each stage of the method of community peer review,

3 and uses a case study to flesh it out. Our marine science laboratory, Civic Laboratory for

4 Environmental Action Research (CLEAR), conducts research on marine plastics in the province

5 of Newfoundland and Labrador, Canada. We research plastic ingestion by fish, birds, and other

6 animals caught for food. Our methods are a product of our own case study of two community

7 peer review meetings based on our research topic and region, though the broader strategies

8 and tactics are applicable to a wide range of research types and sites beyond contamination

9 studies. The details here are provided so readers can gain a sense of which details they might

10 emphasize and adapt in their own use of this method.

\section{Ethics Statement}

The method of community peer review is based on public meetings in public places, gathering information about consent and refusal through observation and surveys, neither of which is meant to be used as data. Rather it is meant to direct and evaluate research. As such, it can be exempt from institutional review under some circumstances. Check with your institutional review board first. Our original data was gathered under an exemption, but we still obtained verbal consent from participants (see step 6 below). The success of the method lead us to want to publish our case studies, which required ethics review for the secondary use of data. We have obtained approval to use data for this publication as per Article 6.3 of the Canadian TCPS2 (ICHER \#20190294-AR). 


\section{Step 1: Hire someone from the community}

2 We cannot stress enough how hiring someone from the community (or communities) you wish 3 to conduct peer review within is required for this method. Researchers from outside of these 4 communities cannot obtain full or nuanced understandings of the existing contexts, histories, 5 needs, and community responses, while a local will already have tacit and experiential knowledge of these elements. When this person (or people) are specifically crucial to an aspect of the method, it is noted explicitly below. The community member should be a full member of your team for the project in general, and the community peer review specifically. This means that if the rest of your team is paid and are expected to come to all lab meetings, so does the community member. In our case, one or more of the lab's research assistants are from the communities we conducted community peer review with, including one student whose thesis project included community peer review [23].

\section{Step 2: Understand social, cultural, and economic contexts of the}

\section{community}

It is crucial to understand the wider historical and political context of the community. Following philosopher Gayatri Spivak we refer to this process as doing our "homework" [24]. There are multiple ways of doing homework to learn to attend to local concerns. For us, homework has included reading texts by Newfoundlanders about Newfoundland, reading local newspapers and Fishermen's Unions annual reports, and as outlined in step 1, the recruitment of local graduate students and field technicians to be part of the process. By doing our homework, we are able to better understand the stakes of our research. It also helps us interpret our results and identify our community (step 3). 
1 In our case, we study the contamination of fish in a place where the fisheries are a major source

2 of employment and culture, particularly in rural communities. Moreover, our study comes 25

3 years after the collapse of the Newfoundland cod fishery in 1992, which was the largest single

4 layoff in Canadian history [6]. This collapse was largely caused by scientific management of the

5 cod stock and the rejection of local fishermen's knowledge $[6,26]$, and impacts how fish

6 harvesters engage with scientists, and government scientists in particular. The collapse

7 devastated the province economically, and the effects remain today, including ongoing

8 community mistrust of fisheries science and management (see results). Though we were not

9 involved in the fisheries science and management that lead to the cod collapse in 1992, as scientists we are still seen as part of that tradition and are responsible to/for this relation, even if we did not cause it [22]. Part of homework should include knowledge about communityinstitutional relationships that you, as a researcher, are already part of.

\section{Step 3: Identify your community}

Which groups are going to be impacted by your work, and how do you tell who belongs in these groups, or communities? This question is difficult to answer, and is part of why having a local community member on the team is imperative. Identifying organized or semi-organized groups is a proxy for identifying community members.

In our case, we were looking for people affected by the contamination of food fish. The Fisherman's Union and local Mini-Aquarium were reliable proxies for some parts of the affected community (for potential economic harm in particular). We also found groups that contained many of the people who lived in the region such as the local dart club (for those who ate local fish). Others could self-identify as community members by answering the open meeting call described below. Finally, we were also able to identify individuals because our laboratory uses 
1 citizen science research methods in most of our sample collection, so we regularly engage

2 directly with community members, particularly people who eat the fish and other animals we

3 sample for plastic ingestion [27]. Having a working knowledge of who is in the community at an

4 individual level will not always be the case, but for us, we know where people fish, where they

5 are from, which radio stations they listen to, and similar details that allowed us to identify and

6 invite a broad spectrum of people within a diverse community that depend on fish and could

7 potentially be harmed by our research or expect benefits from it.

\section{Step 4: Ensure skills for community-based discussion \&}

\section{9 deliberation}

It is too much to expect that scientists have the skills of scientists, social scientists, and public communicators. Yet going into a community meeting without a team skilled in facilitation, ethnographic field methods, and consensus-oriented decision making will not result in community peer review so much as a well-intentioned public presentation of research. You can develop these skills in-house through professional development, or bring in outside people to help with the process:

1) Facilitation: Facilitation is a discussion method that aims to bring collective knowledge together. Rather than styles of discourse characteristic of teaching, knowledge dissemination, leadership, or debate, all of which are largely unidirectional, facilitation looks to address power relations to "[en]sure that everyone gets to participate and share ideas in a meeting, not just those who feel most comfortable speaking up and making cases for their ideas or proposals" by disrupting power dynamics that always exist in group communication [28: p.1,29]. Facilitation is crucial for moving the community meeting from a dissemination-oriented event to an ethics-oriented event. 
2) Consensus-oriented decision making (CODM): CODM is a process where everyone in a group agrees to move forward on a plan of action. This does not mean everyone agrees equally, but that everyone has agreed to move forward regardless of unevenness and differences of opinion. Because it is a method that aims to reach agreement despite difference, it should be carefully and intentionally facilitated. There is a concrete, step by step process that can help a group research consensus [30]. Training in CODM or similar processes is crucial if a community refuses aspects of your research and you have to work together to craft a plan for how information will flow (or not).

3) Ethnographic field notes: Ethnography is a scientific method to "study a culture's relational practices, common values and beliefs, and shared experiences for the purpose of helping insiders (cultural members) and outsiders (cultural strangers) better understand the culture" [31: p.2,32]. Ethnographic observation differs from conventional observation in its explicit attempt to understand other people's behavior on people's own terms and within their context. Ethnographic field notes are "fairly detailed summaries of events and behaviour and the researcher's initial reflections on them," and they "specify key dimensions of whatever is observed or heard" [33: p.447], which become raw data for analysis. Ethnography is common in anthropology, sociology, and other social science fields.

If you do not have people in your research group that are strong in these skills, we recommend hiring or bringing on social science researchers or others trained in these methods.

\section{Step 5: Call the Community Meeting}

It is crucial to call a meeting in a place, at a time, and through methods that are appropriate to the community. You should have learned this through your "homework" (step 2) as well as via the hired community member (step 1). The meeting has to be at a location that community 
1 members can easily access (in their own community is best) and are comfortable in. It should

2 occur at a time that is accessible to most members of the community, and you may choose to

3 run a meeting multiple times if there is no clear choice. Finally, modes of disseminating notice of

4 the meeting should adhere to how community members already communicate.

5

6 In our case, we booked community darts halls in the villages near the wharves where we collected samples rather than holding the community meeting at the university. Booking the hall was also gesture of good faith by spending money in the community. The meeting was held after work and school hours, from 7-8:00pm (once we held a meeting during an evening hockey game and no one attended). We didn't want to take more than an hour of people's time. We advertised the meeting on posters in the area in general stores, directly to core groups such as the Fisherman's Union and Mini-Aquarium, by word of mouth when we collected samples on the wharves, through lab members who were from local communities, in the university events listings, and, most importantly, on the radio via the Fisheries Broadcast, a public local radio show widely listened to by the province's fishing communities.

\section{Step 6: Conduct the community meeting}

\section{Presenting Findings}

Just as in academic peer review, community peer review involves presenting your research question, methods, analysis, and findings to reviewers. For community peer review, there are many ways to do this, but they should always be accessible to the community in both form and content. Avoid or explain jargon or specialized terms, but do not "dumb down" the content.

Community members are intelligent and invested in the research if they have decided to attend the meeting, and you should be ready to present all aspects of the project. We have found that 
1 many fish harvesters, for example, prefer to look at raw data and analyze it for themselves

2 rather than use our statistical analysis of that data, given their expertise manipulating data

3 during their everyday work (sonar, weather, catch rates, price fluctuations). Other community members may prefer to look at summaries and ask broader questions. Providing access to all aspects and data of the project is crucial for informed consent to ensure people have enough information to fully understand the risks or benefits associated with a research project.

Our case covers two separate community meetings spaced a year apart (n1=17, n2=8).

Presentations were similar in format: plastic samples were laid out on tables for visitors to look at before the presentation, and at least one lab member was on hand to answer questions; a slide show was prepared that was image-heavy but did not contain much text (in one case the slide show projected on a screen at the front of the room, and in the other it was on multiple computers and tablets that were passed around a table); there was one main presenter even though many lab members were present (in one case, the presenter was the lab director and in the other it was the community member presenting her thesis findings [23]); the presentation had sections on the overall concerns with plastic pollution, our methods, our findings and their implications; the presentations lasted no more than 20 minutes of the one hour meeting; we used clear, plain language; and we passed around specific samples when we referenced them.

In both meetings, presenters began by saying they were there for community input into the project. This was repeated at the end of the presentation during the discussion period, and a series of questions were asked of the audience, including what they thought of the project, if it aligned with their own experiential knowledge, and if they recognized the sources of plastics from the samples. The audience asked questions of us and held discussions with one another. At the end, presenters asked the audience to fill out a survey for additional input. We stayed at the hall until all community members left to be available for one-on-one discussions. 
2 Crucially, while presenters set up opportunities for refusal and consent throughout the

3 discussion (such as asking whether something seemed right or not or asking if the study should

4 continue during the discussion), we did not explicitly ask for consent to publish the research,

5 even though this was one of our goals. The reason is that we believed that if we framed

6 permission to publish as a yes/no question, non-academics would assume they did not have the

7 authority or expertise to determine this, and we feared we would get consent through community member's deference to our privileged position as university researchers. Moreover,

9 as noted in our discussion of consent, a yes/no framing would miss some of the subtleties of 10 consent and refusal that would indicate where specific messages, methods, or types of 11 circulation might be augmented or abandoned, as outlined in the sections below.

\section{Survey}

A one-page, paper survey was distributed by placing them on the seats before the meeting. It was verbally referenced at the end of the presentation, with assurance that it was confidential and would be used to direct future and current research. We were clear the surveys were optional. The first section of the survey asked where the person was from and what their concerns were about plastic pollution, particularly in their region. The second section asked people to indicate which of the lab's current projects were the most important to work on and continue, including the one being presented on. The third section invited them to participate in future studies. There was a blank comment area at the end.

\section{Ethnographic field notes}

During the meeting, trained lab members took ethnographic field notes. Note takers divided a page into two columns. On one side, the researcher wrote down what she, he, or they saw: 
1 what meeting attendees did, what they said, how many there were, what they looked like, where

2 they sat, what body language they displayed and if/when this changed, and other empirical

3 observations. In the second column, researchers wrote their interpretations of these observations. For example, if someone crossed their arms and scowled when the presenter says, "fish harvesters," the researcher might write that the person did not like that term in the second column of the notebook. These notes detail the entire meeting as people enter and end when all community participants have departed.

In our first meeting, six people took ethnographic field notes. In the second meeting, which was smaller, two people took notes. These two people were also present as notetakers at the first meeting. In all cases, we verbally announced that we were taking observational notes of the meeting and invited participants to signal if they did not want to be included.

\section{Analysis}

\section{Interpreting consent and rejection}

In community peer review, refusal and acceptance are often subtler than people saying outright: "we reject your submission!". Indications and instances may even be contradictory and simultaneous. They will differ among community members. The community may be generous and have good manners when hosting researchers, which may be confused with consent. With this in mind, we analyze our ethnographic field notes, surveys, and other input from community members for both overt and subtle consent and refusal. By overt, we mean actions that directly and explicitly relay consent, refusal, approval, or disapproval about research activities. These may include invitations for continued research (approval) or combative language about results (refusal). Subtle acceptances and refusals are more common [20]. Examples of these are 
1 suggestions to study elsewhere or withholding information (refusal) [1] and lingering after

2 presentations to speak with presenters (approval).

\section{Analyzing field notes}

4 We analyzed field notes in two ways. Immediately after each meeting, the entire team debriefed,

5 and each person discussed what they thought were the most significant moments during the

6 meeting and their overall impressions. This allowed us to immediately identify agreements and disagreement in observations and interpretations across notetakers, and we could bring multiple perspectives to bear on disagreements. This validates results across notetakers. The notes themselves were coded for moments of refusal and acceptance; signs of refusal were highlighted in red, and signs of consent were highlighted in green.

We do not rely on body language studies for this analysis. We have found that body language and other behaviours are culturally-specific. Answering a cell phone in a classroom is highly rude, while it is normal and acceptable in some community settings. The culturally-specific analysis of body language, spoken statements, and other behaviours observed in field notes requires the input of the hired community member (step 1).

\section{Analyzing surveys}

Surveys were analyzed for the percentage of participants who filled them out (an indication of the willingness to participate in an optional activity) as well as for survey content. Content analysis included the percentage of participants who indicated that the research being presented was important (especially compared to other research the lab was doing), whether and to what degree participants added extra value to the surveys by filling in "other" categories, wrote beyond the questions asked, or used inscription techniques such as exclamation points, 
1 stars, bolding, or scratching out to augment meaning. These were analyzed individually and in

2 aggregate to see if there were differences between individual versus community-level consent 3 or refusal.

\section{Validation}

5 Triangulation was used to validate results [33]. Findings were cross-checked through comparing 6 the findings from the surveys with the ethnographic field notes, and through comparing different 7 researchers' field notes.

\section{Results}

\section{Signs of consent and approval}

10 We saw signs of consent, approval, and ratification that we felt we could differentiate from 11 neutrality, mild acceptance, and good manners. Some of these were overt and clear (Table 1). For example, one attendee approached the lab director after the meeting to say they had attended with the intent of arguing with us if we said the fish were "dirty," but that we had true results, so they did not have to "fight" us. This person later partnered with the lab to obtain samples and host trainings. In other instances, people verbally agreed with statements by saying "yes" out loud during the presentation, or wrote on surveys that they wanted to participate in future studies. Usually though, indications were subtler. For example, at our request attendees looked at our samples of ingested plastic and offered their suggestions for where they thought they might be originating from, given their expertise with fishing gear and local waste sources. Not only did they oblige, which may have been a form of generosity or good hosting rather than consent, but they also wrote down their insights for us, which was not at our request. We interpreted this as approval. On surveys, most attendees indicated that the 
1 study presented during community peer review was the most important study the lab was

2 conducting among all our other projects (meeting 1: $12 / 17$ surveys or $70.6 \%$; meeting 2: $8 / 8$

3 surveys or $100 \%$ ). 
1 Table 1: Observations of overt and subtle consent of research during community peer review

\begin{tabular}{|c|c|c|}
\hline \multicolumn{2}{|c|}{ Interpretation } & Observation \\
\hline \multirow{6}{*}{$\stackrel{\frac{\pi}{0}}{O}$} & Acceptance & $\begin{array}{l}\text { Attendee saying they were not going to argue with us as anticipated, since we } \\
\text { had "good" results }\end{array}$ \\
\hline & Acceptance & $\begin{array}{l}\text { Two people in the back row verbally agreeing with presenter, saying "yeah" out } \\
\text { loud to each other repeatedly }\end{array}$ \\
\hline & Acceptance & $\begin{array}{l}\text { Participant asks the lab to conduct a study on mackerel, echoed by other } \\
\text { participants (head nodding, saying "yeah") }\end{array}$ \\
\hline & Acceptance & $\begin{array}{l}\text { People filled out the survey to say they want to participate personally in future } \\
\text { studies, including answers such as "Doing anything!" with exclamation point and } \\
\text { a request to become a lab team members }\end{array}$ \\
\hline & Acceptance & $\begin{array}{l}\text { Attendee invited researchers to work in their home village via the Q\&A, after the } \\
\text { presentation, and via the survey }\end{array}$ \\
\hline & Acceptance & Writing down insights for us on the survey when they were not requested \\
\hline \multirow{10}{*}{$\frac{\oplus}{\frac{\oplus}{\overrightarrow{0}}}$} & Acceptance & $\begin{array}{l}\text { Widespread nodding and smiling at specific parts of presentation, including: } \\
\text { concept of citizen science, discussing research focus on cod, mention of } \\
\text { importance of studying wild food, discussion of microfibers from washing } \\
\text { machines, mention of the importance of long-term monitoring }\end{array}$ \\
\hline & Acceptance & $\begin{array}{l}\text { Attendees wanted us to talk to the Department of Flsheries and Oceans (DFO) } \\
\text { about eliminating proposed plastic fish tagging system, presumably using our } \\
\text { data as evidence }\end{array}$ \\
\hline & Acceptance & $\begin{array}{l}\text { Excited participant comment that plastics were found in adjacent community, not } \\
\text { their own }\end{array}$ \\
\hline & Acceptance & $\begin{array}{l}\text { A partnership with a local community-based organization (CBO) emerged after } \\
\text { their director attended our public meeting }\end{array}$ \\
\hline & Acceptance & $\begin{array}{l}\text { Participants pass around plastic samples, talking to one another, identifying } \\
\text { potential sources, taking significant time with each }\end{array}$ \\
\hline & Acceptance & $\begin{array}{l}\text { On the surveys, indication that we should study plastic ingestion in capelin, } \\
\text { mackerel, and other pelagic fish in addition to cod (though not indicating we } \\
\text { should study it there) }\end{array}$ \\
\hline & Acceptance & Participants advances the slides for us during table-top presentation \\
\hline & Acceptance & $\begin{array}{l}\text { In Q\&A asking entire group what "we" (research group) can do about new } \\
\text { government fish tagging proposal }\end{array}$ \\
\hline & Acceptance & $\begin{array}{l}\text { Via survey, request to study plastics in an area where the respondent was from } \\
\text { (invitation) }\end{array}$ \\
\hline & Acceptance & $\begin{array}{l}\text { Audience member asked if we had any papers published, and asked for website } \\
\text { where papers would be published in the future }\end{array}$ \\
\hline
\end{tabular}




\begin{tabular}{|l|l|l|}
\hline Acceptance & $\begin{array}{l}\text { On the surveys, consistently saying we should continue to study cod (in second } \\
\text { meeting, 100\% of surveys indicated this). }\end{array}$ \\
\hline Acceptance & $\begin{array}{l}\text { Though optional, almost everyone filled out a survey at both meetings (case 1: 17 } \\
\text { of 22/25, but some pairs of people did one survey; case 2: 8/13, but some pairs } \\
\text { filled out surveys together as well). }\end{array}$ \\
\hline Acceptance & $\begin{array}{l}\text { Many questions during Q\&A, particularly in terms of asking researchers to } \\
\text { discuss local plastic phenomena people are concerned about, such as } \\
\text { microplastics in seaweed, where plastics in certain bays are coming from, etc. }\end{array}$ \\
\hline Acceptance & $\begin{array}{l}\text { In Q\&A, admitting to burning waste (illegal activity) } \\
\text { People linger after the meeting to talk to researchers, look at samples, stand } \\
\text { around, fill out surveys }\end{array}$ \\
\hline Acceptance & $\begin{array}{l}\text { On surveys, most attendees indicated that cod study, which was presented, was } \\
\text { the most important study the lab was doing (case 1: } 12 / 17 \text { surveys or } 70.6 \% ; \\
\text { case 2: 8/8 surveys or } 100 \%)\end{array}$ \\
\hline Acceptance & $\begin{array}{l}\text { During discussions, an attendee stated that replicability of the plastic ingestion } \\
\text { study over time was important (though again, not specifically in the area) }\end{array}$ \\
\hline
\end{tabular}

\section{Signs of Refusal, Repair, and Amendment}

3 As with consent, some refusals were overt, but most were subtle (Table 2). One of our overt examples of refusal came after participants made negative jokes and comments about the

5 Department of Fisheries and Oceans (DFO) (the federal government body that oversees

6 fisheries management). One person asked if we worked with or for DFO, loudly. We knew this would likely occur from doing our "homework" (step 2). When we explained the extent of our experience with DFO (limited to data collection in some studies, though not the one we were presenting), they relaxed somewhat, but it was clear that we would not be welcome to collect samples in their area if we worked with DFO, and it was explicitly requested that insights we gained during the course of community peer review should not be shared with DFO. We understand this refusal as repair of existing schisms between fishing communities and researchers, given the history of the region where the DFO managed the cod population into 
1 "annihilation" that resulted in massive, damaging changes to life and livelihood in the region [6].

2 In another overt case, a fisherman stood up to ask if our results would impact the market price

3 of cod, indicating an area of potential risk and harm. We had to conduct research to see if this

4 had occurred in any other cases of reporting contamination (to our knowledge it had not, which

5 we reported back). Other instances were subtler, such as when attendees consistently indicated

6 on the survey that we should continue biomonitoring studies but did not rank our other projects,

7 such as shoreline and surface water studies. In this case, both "no" and "not yes" are interpreted

8 as refusal. This input has directed our overall research program and we focus on biomonitoring

9 wild food rather than on shoreline and surface water studies.

10

Table 2: Observations of overt and subtle refusal of research during community peer review

\begin{tabular}{|c|c|c|}
\hline \multicolumn{2}{|c|}{ Interpretation } & Observation \\
\hline \multirow{2}{*}{$\overbrace{0}^{\frac{\pi}{0}}$} & Refusal & $\begin{array}{l}\text { Attendees made disparaging or negative jokes and comments about DFO, then } \\
\text { asked if we worked for or with them; this was a refusal of collaboration with DFO and } \\
\text { DFO research generally }\end{array}$ \\
\hline & Refusal & $\begin{array}{l}\text { Question during Q\&A about whether the market price in cod from the area would } \\
\text { fluctuate after findings are published }\end{array}$ \\
\hline \multirow{6}{*}{ 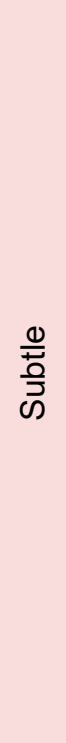 } & Refusal & One survey respondent circled all studies as "important" but prioritized them \\
\hline & Refusal & No one sat in the front row \\
\hline & Refusal & One person left the meeting early \\
\hline & Refusal & $\begin{array}{l}\text { Participant answered phone and had a conversation during meeting, still sitting at the } \\
\text { table (though our local hire told us this was culturally normal and not necessarily a } \\
\text { sign of refusal) }\end{array}$ \\
\hline & Refusal & $\begin{array}{l}\text { One survey response answered the top portion (concerns and locale), but not the } \\
\text { second part (importance of research) }\end{array}$ \\
\hline & Refusal & $\begin{array}{l}\text { On surveys, the most important research projects for attendees were highlighted, and } \\
\text { by extension unimportant projects were also made known. For example, no one in } \\
\text { case } 2 \text { thought that silver hake was an important species to study, and only } 3 \text { of } 8 \\
\text { people thought studying birds that are not consumed for food was important. Note } \\
\text { that there was no option to mark what studies were NOT important, which would be a } \\
\text { way to gain overt refusal }\end{array}$ \\
\hline
\end{tabular}




\section{Refusal moving into consent $(\mathrm{H} 2)$}

2 Some refusal moved into consent (Table 3). During our first public meeting, at first attendees

3 listened with arms crossed, with little or no verbal input, and without speaking to their

4 neighbours. Then we revealed the frequency of ingestion of plastics by cod, our main finding-

5 we found one of the lowest ingestion rates recorded in published literature at the time, indicating

6 the local fish were less polluted than other fish of the same species in similar areas [27]. People

7 uncrossed their arms, leaned back in their chairs, started joking with one another, and began

8 calling questions and points out to us as we presented. The entire mood of the room shifted

9 from tension (refusal) to comfort (consent). We consider this one of the most notable findings in

10 our case study, as it implies that attendees were concerned about our results and may well

11 have been primed to refuse part or all of the research, but that once findings were discussed,

12 they accepted the research as they believed it would not cause harm. We argue that

13 considering these shifts, rather than focusing on isolated behaviours, are crucial for interpreting

14 refusal and consent.

15

There were no examples of observed consent moving into observed refusal.

Table 3: Instances of overt and subtle shifts from refusal to consent of research during

community peer review

\begin{tabular}{|l|l|l|}
\hline \multicolumn{2}{|c|}{ Interpretation } & \multicolumn{1}{c|}{ Observation } \\
\hline \multicolumn{2}{|c|}{$\begin{array}{l}\text { Refusal to } \\
\text { consent }\end{array}$} & $\begin{array}{l}\text { When asked for consent to be photographed, two attendees said no. After } \\
\text { learning that images would be used in publications and online, one attendee } \\
\text { changed their mind and consented to photographs. The other verbally said it was } \\
\text { fine, but their tone, body language, and word choice indicated refusal. WE did } \\
\text { not photograph the second person. }\end{array}$ \\
\cline { 2 - 3 } & $\begin{array}{l}\text { Refusal to } \\
\text { consent }\end{array}$ & $\begin{array}{l}\text { Attendee directly asks co-presenter, "What's your affiliation with DFO?" There } \\
\text { were previous discussions about community dislike/distrust of DFO, and } \\
\text { presenters had already said they did not work with DFO. Accepts presenter's } \\
\text { assertion that we did not work with DFO on this project. }\end{array}$ \\
\hline
\end{tabular}




\begin{tabular}{|c|l|l|}
\hline & $\begin{array}{l}\text { Refusal to } \\
\text { consent }\end{array}$ & $\begin{array}{l}\text { At start of meeting, one attendee says out loud to no one in particular, "There's } \\
\text { no plastics in the cod here, I can tell you that." They did not nod when findings } \\
\text { were presented (unlike most others around them), but did approach the } \\
\text { presenter after the meeting to agree with findings ("I knew the fish were good } \\
\text { here!") and asked to partner with the project. }\end{array}$ \\
\hline$\frac{0}{\frac{0}{\overrightarrow{0}}}$ & $\begin{array}{l}\text { Refusal to } \\
\text { consent }\end{array}$ & $\begin{array}{l}\text { At the beginning of the public meeting, attendees were tense with crossed arms, } \\
\text { little conversation, not laughing at jokes much. After results were shared, } \\
\text { attendees relaxed body language, and they laughed and spoke out of turn. }\end{array}$ \\
\hline
\end{tabular}

\section{Discussion}

3 So how do we take these findings-some refusal, mostly consent- and make decisions about

4 the circulation of research? In some cases, we might look at the density, intensity, and

5 consistency of consent and refusal and look for patterns. It is crucial that "voting" is not part of

6 this analysis, where a majority is seen to indicate refusal or acceptance, given that communities

7 are not homogenous and will always contain different interests, vulnerabilities, and knowledges.

8 Voting would systematically disenfranchised and/or harm one portion of the community, which is

9 what community peer review aims to reduce or eliminate. In terms of individual versus

10 community consent, we should note whom is consenting and refusing as part of our

11 interpretation. In some cases of research with high stakes it would be appropriate that

12 consensus is required and one refusal is enough to refuse the entire project. In other, lower

13 stake situations, it may not be the entire project that is being refused and amendments and

14 changes might be enough to address the main underlying issues. Interpreting refusal and

15 consent is a collective judgement based on engagement with the specific contexts and stakes of

16 the research. This requires working with community members closely, and is why it is crucial to

17 have at least one paid community member as part of the research team for this method. 
1 The step-by-step outline provided here is designed as a loose protocol to be adapted to local

2 circumstance, culture, and science. Yet there are two interpretive guidelines for community peer

3 review that we believe are crucial and should not be altered: 1) Err on the side of refusal, both

4 when it is not clear whether something is acceptance or generosity (assume generosity), or

5 when there is one strong refusal amidst varieties of acceptance $[2,18,19] .2)$ Interpret with

6 community members. Extracting data and decontextualizing it within the academy is the reason

7 we are proposing community peer review as a method to begin with, so patterns of

8 decontextualization should be rigorously avoided.

9

Overall, we interpreted our community peer review sessions to indicate that we could publish

our results. This has since been strengthened by requests by attendees for the articles themselves. At the same time, we are paying heed to the various refusals of certain aspects of our research and are changing our practices accordingly. We now focus on ingestion studies over shoreline studies, as those have consistently been articulated as more important, and are careful about what kind of partnerships we enter into, with whom, and how data is shared between partners. By directing our research so that it is more relevant to local needs and is responsive to existing power relations, community peer review offers similar gains to academic peer review.

If the community had refused our research project, we would have worked with them on where and how the knowledge we created should best exist. Perhaps our findings would have created harm if published in academia or in the media, but would be important for the Fisherman's Union, local fish harvesters, pregnant women, or other key groups. In that case, we would have used consensus-oriented decision making [30] to collectively decide the way that the data would add the most value and avoid harm for the community. 
1 One of the most common questions we receive about this method is about what to do about the

2 many different communities that have stakes in our research. In our case, for example, not just

3 local people who eat fish, but also commercial fish harvesters, other scientists in the same field,

4 and the plastics industry can be understood as communities with a stake in our research on

5 plastic contamination of wild food. This can be addressed by differentiating between equity and

6 equality, and the role of each in accountability. Equality means treating everyone the same. Yet

7 because people and groups start from very different social locations (rural people in

8 Newfoundland who depend on fish versus the plastics industry for example), treating different

9 people the same can reproduce, and even exacerbate, unevenness and injustice. The classic example is testing the fitness by asking both a tiger and a shark to climb a tree. We want to avoid this kind of equal treatment.

Equity, on the other hand, is a framework that seeks to identify and address these differences.

Community peer review works from an equity framework, aiming to correct the structure where researchers have considerable autonomy and power over how they represent the world in their research, and often cause damage to communities in the process, while communities have little

17 to no autonomy over how they are represented in research. This process aims to make researchers accountable to this power dynamic. Community peer review is about not giving everyone the "same" rights to gain, access, or disseminate data because an evenness in those rights does not (yet) exist. Community peer review is designed as a solidarity research methodology that addresses the unevenness of existing communities-academic, industry, government, local—in scientific research. 


\section{Acknowledgements}

2 We acknowledge that this research was conducted on the unceded, unsurrendered ancestral

3 Lands of the Mi'kmaq and Beothuk. We would also like to acknowledge the Inuit of Nunatsiavut

4 and NunatuKavut and the Innu of Nitassinan, and their ancestors, as the original peoples of

5 Labrador.

6 We owe a great debt of thanks to the many community members who attended our public meetings and participated in various stages of our fish ingestion studies. We also thank CLEAR lab members who helped with these meetings and nuanced our thinking about this project. In particular we thank Jess Melvin who conducted a cod ingestion study and presented at a community meeting as part of her thesis work.

This project was funded by the Social Science and Humanities Council of Canada (SSHRC) Insight Development Grant (430-2015-00413) for initial data collection, and through Insight Grant (435-2017-0567) for development and publication of the method of Community Peer Review.

\section{References}

1. Simpson A. On Ethnographic Refusal: Indigeneity, 'Voice' and Colonial Citizenship. Junctures: The Journal for Thematic Dialogue. 2007;9: 67-80.

2. Simpson A. Mohawk interruptus: Political life across the borders of settler states. Durham: Duke University Press; 2014. 1998. 
1 4. Brandt AM. Racism and research: The case of the Tuskegee syphilis study. Hastings Cent

2 Rep. 1978;8: 21-29.

5. Zimbardo PG. On the ethics of intervention in human psychological research: With special reference to the Stanford prison experiment. Cognition. 1973;2: 243-256.

6. Bavington D. Managed annihilation: An unnatural history of the Newfoundland cod collapse. Vancouver: UBC Press; 2010.

7. Dewailly E, Nantel A, Weber J-P, Meyer F. High levels of PCBs in breast milk of Inuit women from Arctic Quebec. Bull Environ Contam Toxicol. 1989;43: 641-646.

8. Harmon A. Indian tribe wins fight to limit research of its DNA. The New York Times. $21 \mathrm{Apr}$ 2010. Available from: https://www.nytimes.com/2010/04/22/us/22dna.html. Cited 14 May 2018.

9. Skloot R. The immortal life of Henrietta Lacks. New York, NY: Broadway Press; 2010.

10. Tuck E. Suspending damage: A letter to communities. Harv Educ Rev. 2009;79: 409-428.

11. Usher PJ, Baikie M, Demmer M, Nashima D, Sevenson MG, Stiles M. Communicating about contaminants in country food: The experience in Aboriginal communities. Ottawa: Inuit Tapiriit Kanatami / Inuit Tapirisat of Canada; 1995.

12. Canadian Institutes of Health Research, Natural Sciences and Engineering Research Council of Canada, and Social Sciences and Humanities Research Council of Canada. Chapter 3: The consent process. In: Tri-council policy statement: Ethical conduct for research involving humans. December 2014. 
1 13. American Indian Law Center. Model tribal research code. 3rd ed. Albuquerque: American Indian Law Center; 1999.

14. Hayden C. Taking as giving: Bioscience, exchange, and the politics of benefit-sharing. Soc Stud Sci. 2007;37: 729-758.

15. Wallerstein NB, Duran B. Using community-based participatory research to address health disparities. Health Promot Pract. 2006;7: 312-323.

16. Ahmed S. Willful subjects. Durham: Duke University Press; 2014.

17. Simpson A. Consent's revenge. Cult Anthropol. 2016;31: 326-333.

18. May E, Blue Seat Studios. Tea and consent [Video]; 2015. Available: https://www.youtube.com/watch?v=pZwvrxVavnQ

19. Tuck E, Yang KW. R-Words: Refusing Research. In: Paris D, Winn MT, editors. Humanizing research: Decolonizing qualitative inquiry with youth and communities. Thousand Oaks: SAGE Publications; 2014. pp. 223-247.

20. Tuck E, Yang KW. Unbecoming claims: Pedagogies of refusal in qualitative research. Qual Inq. 2014;20: 811-818.

21. Coulthard GS. Red skin, white masks: Rejecting the colonial politics of recognition. Minneapolis: University of Minnesota Press; 2014.

22. Smith LT. Decolonizing methodologies: Research and Indigenous peoples. London: Zed Books; 1999.

23. Melvin J. Plastic ingestion in Atlantic cod (Gadus morhua) on the east coast of Newfoundland, Canada: results from a citizen science monitoring project, with policy 
recommendations for long-term monitoring. M.Sc.Thesis, Háskólasetur Vestfjarða / University Centre of the Westfjords. 2017. Available from: https://skemman.is/handle/1946/28666.

24. Spivak GC. The post-colonial critic: Interviews, strategies, dialogues. New York and London: Routledge; 1990.

25. Sundberg J. Decolonizing posthumanist geographies. Cult Geogr. 2014;21: 33-47.

26. Murray G, Bavington D, Neis B. Local ecological knowledge, science, participation and fisheries governance in Newfoundland and Labrador: A complex, contested and changing relationship. In: Gray TS, editor. Participation in fisheries governance. Dordrecht: Springer; 2005. pp. 269-290.

27. Liboiron M, Liboiron F, Wells E, Richárd N, Zahara A, Mather C, et al. Low plastic ingestion rate in Atlantic cod (Gadus morhua) from Newfoundland destined for human consumption collected through citizen science methods. Mar Pollut Bull. 2016;113: 428-437.

28. AORTA. Anti-oppressive facilitation for democratic process: Making meetings awesome for everyone. AORTA. June 2017. Available from: http://aorta.coop/wpcontent/uploads/2017/06/AO-Facilitation-Resource-Sheet.pdf. Cited 14 May 2018.

29. Otim RL. Facilitation Skills Training Manual: A facilitator's handbook. Kampala, Uganda: AVSI; 2013.

30. Hartnett T. Consensus-oriented decision-making. Gabriola Island: New Society Publishers; 2011. 
1 31. Ellis C, Adams TE, Bochner AP. Autoethnography: An overview. Forum Qual Soc Res.

2 2011;12. Available from: http://www.qualitative-

3 research.net/index.php/fqs/article/view/1589

4 32. Maso I. Phenomenology and ethnography. In: Atkinson P, Delamont S, Coffey A, Lofland 5 J, Lofland L, editors. Handbook of ethnography. Thousand Oaks: SAGE; 2007. pp. 1366 144.

7 33. Bryman A. Social research methods. 4th ed. Oxford: Oxford University Press; 2012. 